\title{
The effectiveness of the interaction of interactive book Cues and levels of information processing on learning retention and external cognitive load
}

\author{
Usama M. Ibrahem ${ }^{1,4, *}$, Saleh A. Alkhabra ${ }^{2}$, Bader A. ALharbi ${ }^{3}$ \\ ${ }^{1}$ Department of educational technology, University of Hail, 2440, Hail- KSA \\ ${ }^{2}$ Department of educational technology, University of Hail, 2440, Hail - KSA \\ ${ }^{3}$ Department of Curricula and Teaching Methods, University of Hail, 2440, Hail - KSA \\ ${ }^{4}$ Department of educational technology, Suez Canal University, 41522, Ismailia - Egypt
}

Received: February 14, 2021. Revised: March 30, 2021. Accepted: April 2, 2020. Published: April 7, 2021.

\begin{abstract}
This study explores interactive e-book cues and Information Processing Levels (IPL)'s effectiveness on Learning Retention (LR) and External Cognitive Load (ECL). 117 middle school pupils (MSP) were divided into six experimental groups based on their IPL and cues during the second term of the academic year 2019-2020. Visual Cues (VC)/Audiovisual Cues (VAC) and Auditory Cues (AC)/Audiovisual Cues (VAC) statistically varied in the Ie-book in LR test and ECL scale, same for the average scores when testing the LR in Science for MSP due to the difference between IPL for the DL. There is a statistically significant effect of cue types' interaction in Ie-book with IPL in ECL scale for MSP, at its highest peak in the case of the AVC with DL, followed by the interaction resulting from the VC with DL then AC with SL. Also, cues interaction in Ie-book with IPL immensely affect the LR test for MEP, which is at its highest peak in the case of the AVC with DL. The interactions between (DL-SL) and $(\mathrm{AC}-\mathrm{VC})$ seem to equally influence the ELC
\end{abstract}

Keywords - Interactive e-book (Ie-book)- Cues- Visual Cues (VC)- Auditory Cues (AC)- Audiovisual Cues (AVC)- Information Processing Levels (LIP)- Surface Level (SL)- Depth Level (DL)- Learning Retention (LR)External Cognitive Load (ECL)- Middle school pupils (MSP).

\section{INTRODUCTION}

Today's children are digital natives. Their lives directly or indirectly involve online interaction with others [1]. Ie-book is an e-learning source that overcomes restrictions of paper books, increasingly motivating learners via a variety-rich media, besides being an effective e-learning tool where learners watch, enjoy, and practice. E-books are interactive and facilitate the learning process; the form of information contributes positively to value estimation. So, e-books considerably garnered attention, now implemented into various educational stages from the primary stage to university education, facilitating learner-content interaction to achieve effective active learning [2],[3].

Rather than just decoding a printed text or listening passively to an audiobook, the learner somehow leads the interactive experience as an active participant in the two-way process of storytelling [4]. Digital publishing platforms offer various ebooks features, where the device-agnostic learning experience is interactive. Interactivity can be utilized for better engagement. Likewise, K12 and higher education institutions can utilize Ie-book to ensure better subject retention by students [5].

Cues are a critical advantage of Ie-book that rely on visual and auditory attractions. [6] Defines cues strategies as the process of focusing the learner's attention on individual stimuli during the presentation of the content to distinguish the basic learning features to single out the education. Cues internally motivate learners to solely interact with the stimuli, improving the educational process and its and strategies [7]. Forgetfulness 
results from misused cues. However, learned information are present and stored in individuals' memories; appropriate cues are the key related to the individual's information. Retrieving information is easy and possible with proper cues.

[8],[9] Mention audio, visual, text, and audiovisual cues. Learning concepts necessitates visual and nonvisual cues directing the learner's attention to the common characteristics while focusing on the educational content, double coding it in learner memory, and influencing the learner's recalling.

Individual differences, among other factors, affect information processing. A dedicated field focused on individual differences emerged to assess information processing, where learning, IPL wise, is knowledge building. Information mental representation is a multilevel complex process including physical and symbolic representation [10].

CL's literature indicates that learned material's recovery correlates to the subject's level of receipt and preparation, whether SL, intermediate level, or DL. Per the IPL model, the deeper processing of the learned material, the greater the mental effort is exerted [11]. IPL strongly incites achievement in terms of cognitive activity form rather than content; the processing information method can showcase how a person thinks, expressing human preference to information receipt [12].

The CL theory closely relates to the teaching and learning process, based on our knowledge of a human's cognitive structure. Cognitive structure lacking-models of education are inefficient [13]. The theory describes learning structures from the perspective of an integrated information processing longterm memory system that stores knowledge acquired relatively permanently within the working memory [14]. The theory allows devising the effective support of learning through the teaching process, where information processing problems arise when an individual is over-fluxed with elements simultaneously. [6] Indicates that using untested cues in multimedia overloads cognition. [15] added that too many cues cause CL burdens; the audiovisual information processing channels are limited based on experience and information.

Reducing cognitive overload and improving learning experience effectiveness is key. IPL avails general guidelines on how the student processes information. Cues' Ie-book utilization in an ill-considered manner constituting a CL that hinders students' learning.

Providing courses with varied content, such as a science course (given that it includes various concepts, information, skills, and experiences) requires students to use types of cues. That facilitates linking concepts, elements and linking them together in an e-learning environment that enables students to acquire these concepts, information, and skills effectively contained in the content.

\section{SEARCH PROPLEM}

By examining some of the available e-books at different academic levels (Science, Mathematics, and Social Studies), it turned out that most of them focus on the visual aspects of the printed book and replace its physical properties such as size and quality with visual characteristics, maintaining the same form. These paper-to-visual books mostly lack cues. Therefore, researchers conducted some free-discussion interviews with $30 \mathrm{MSP}$ and 10 teachers, discussing available e-books and their factors. They confirmed that the e-books known to them are the only text-to-PDF files lacking interaction and multimedia. They wished to have e-books containing videos and audio files supporting the learning processes of scientific subjects.

Studies have focused on technology application in e-books and their importance in learning efficiency [15]-[19] without considering learners' differences and associated CL. Concerning cues' effectiveness, some studies confirmed that there are no cue type-induced differences [20],[21], while others claim otherwise. Research also revealed the effect of IPL differences on performance.

Research concludes that cues play a role in multimedia design; it draws the learner's attention toward the learning focus, adequately appropriating the visual, verbal, and audio stimuli display environment to stimulate the learner's motivation. Alternatively, this may impact courses with diverse content, e.g., Science due to the variety of concepts, information, skills, and experiences. Their presentation requires types of cues that facilitate linking concepts and elements in a learning eenvironment that enables students to acquire concepts, information, and skills effectively.

Accordingly, the research problem determined in the weak use of e-books due to the poor quality of the current e-books in achieving the desired goals due to design criteria and lacking consideration of learning theories and IPL. Also, the cues were not employed in the e-books in a way that reduces the cognitive load and improves the learning outcomes.

\section{LITREATURE TEVIEW}

Ie-book:

Ie-book immerses readers in content and creative thinking, wherein each bit of content functions as a standalone part of the whole. Interactive content maintains a visuals-over-text emphasis. IeBs are digital books with multimodal enhancements such as sound, animation, and narration. Iebook can potentially alter reading due to their interactivity. Their technical qualities are [22]-[24]:Flexible Commands, Organized Typographical Design, Cognition Tools, Customizable-to-Learning Style, and Interactive Medium. [25] advised that interactive sequences should augment and illustrate the text, advance the story, and provide clear signals when the interaction is triggered.

Ie-book Role in Technology-Enhanced Learning

Ie-book software applications avail a multimedia literary experience customized for touch screen devices. Ie-book hotspots-friendly applications allow readers active involvement [2].

E-books improve student comprehension and retention [22]. Research confirmed that e-books develop various aspects of learning due to audio and visual stimuli. [26]-[30] pointed to e-books' effectiveness in achievement, learning efficiency, and 
the development of innovative thinking due to the different multimedia elements and structural learning support. [31] Also found a positive relationship between navigation methods and cues (especially AVC) in e-books and attitude toward easy reading. Cue-rich e-books allow active learning and less CL [7]. Also, [2], [24] [32] suggest that IeB's future might have enhanced engagement and motivation and knowledge building. Teachers can easily create Ie-book for use on mobile devices thanks to tools such as "iBooks Author"; [33],[34].

Ie-book and Cues' Types in the Light of Learning Theories

The Binary Coding Theory assumes that within the human mind two channels of coding information exist: The first is for verbal coding language. The second is for coding nonverbal language (pictures, drawings, etc.). Students can mentally connect verbal and nonverbal stimuli. The duplication and interconnection of information (with cues) transfer channels improve memory functions. Per the CL theory, learning is a process altering the information network with long-term memory, which affects the learner's performance. CL reduction within the working memory facilitates information network alteration with long-term memory [35],[36]. With cues, this can be provided by the IeB.

The Multimodal Learning Theory states that learners establish and demonstrate understanding through different modes within print and screen-based technologies [37]. IeB's embedded hotspots allow readers a direct involvement with the text to activate and control animations, sounds, and activities. IeB's activities allow a semblance of control for the learner, eliciting sensory or cognitive curiosity [38]. Learner control is a significant feature of Ie-book applications; the reader can shape, expand, and determine paths to access content as a part of the reading process [2],[39].

Cues' Educational Roles

[40],[41] define cues as stimuli that help draw the learner's attention to the concepts' distinctive characteristics and minimize the emergence of irrelevant elements. [40] Identified a group of cues types for direct attention and perception: colors, arrows, lines, shading, contrast, motion, visual impact, size control, font type, bordering mode, encircling mode, multiple exposure, labeling, stimulus intensity, and advanced organization.

Cues improve learning outcomes, help to focus attention, and use appropriate symbols for processing and storing in memory, i.e., increasing the learner's retention of information. Cues direct learners 'attention to the content's important parts, facilitating their selection. Cues affect immediate and delayed understanding and help learners maintain visual and verbal representations in their working memories [20],[24],[27], [40],[41]. Cues fall under two strategies: one that aims to provide learners with additional stimuli to improve' understanding and complement the received information, While the other focuses attention on the to-be-learned educational stimuli [40].

Cues Design Criteria:

Cues' criteria are necessary for effectiveness and promotion of learning. [31] Criteria are visual stimuli extracted from learning theories: abstraction and comprehensiveness, singular-concept focus, rug, balance, realism, organization, harmony, inclusiveness, and clarity.

[43] Defined eight criteria crucial to designing cues: simplicity, clarity, organization, context, shape, and floor, balance, similarity, and stability. [28],[44] pinpointed several constructive criteria for designing cues-based programs, of which the most important are the following: First, Educational criteria include educational activities indicators, linked to program use, educational content, the targeted learners, and methods of content presentation. Second, technical criteria include four indicators, interface, clarity and focus for effective functions, and gravity and excitement to direct students' attention, displayed content appropriation, and relevance to the goals. Third, technology criteria include four indicators, functionality, display elements, learner clarity, and color consistency.

IPL

It is a method of encoding information and stimuli. IPL differences are located on a continuum that extends from the $\mathrm{SL}$ in the treatment to the DL, focusing on the meaning. There are three levels of cognitive processing and information processing, differing in processing depth. First, the SL preparation is where the individual handles information whether physically or otherwise and the context in which the information is presented [45]. Second, the intermediate level is where the learner deciphers the apparent text by recognizing crosschecking vocabulary or paragraphs, focusing on the sound of the word. Third, the DL is where the educated level that directs its attention toward the content of the learning subject is adopted, i.e., dealing with the purpose of the content. It strives to reach the meaning deduced from the task to achieve the author's goal [46].

IPL and LR

Information processing initial stages necessitate receipt and follow-up on situation-related information. Successful information acquisition depends on the effectiveness of many factors, e.g., sensory recorders, processing speed, selective

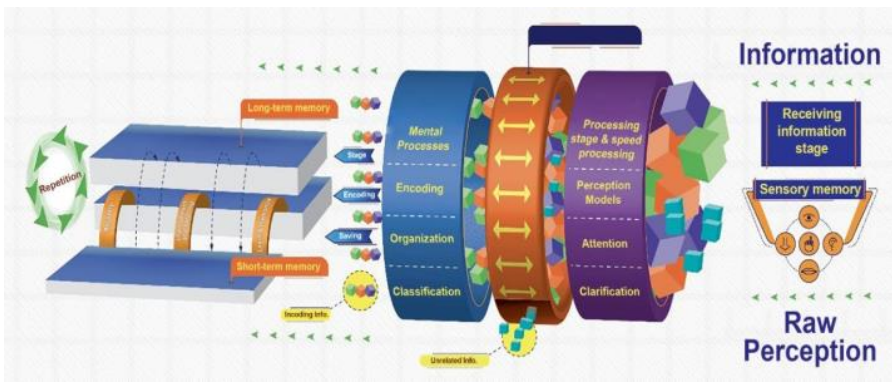

Fig. 1 Stages of processing information by Ibrahem (2017)

attention, and coding [47], as shown below:

First, receiving and processing information is where the information are received in sensory records (sensory memory) as raw perception that ranges between $0.5-1$ seconds, where some concepts are converted to short-term memory. Second, the processing speed represents is measurable through a rapid succession of paragraphs. Third, is the selective attention phase. Fourth, coding represents information after being 
recorded by sensory recorders in short-term memory or longterm memory. Educational programs must employ all this to achieve the learning outcomes and make it RL.

CL in Learning

[34] defines CL as "the amount of mental energy needed to process the amount of information provided by the learner at a time and refers to the amount of mental activity imposed on working memory."

CL sources are divided into three types. The first is the intrinsic load resulting from the complex nature of the information, determined mainly by the information's internal interaction and the number of cognitive elements that must be maintained at one time in the working memory [36]. Secondly, the extraneous load is an extended load mainly through an educational form. Third, closely related load that is formed when the learner participates in the intended process to address the knowledge that leads to constructing the cognitive plan [49].

[50]-[52] found VC's effectiveness in multimedia and CL reduction. as Lin, L., reducing cognitive overload and retention and recall abilities.

The IPL (SL/DL) is an important variable that may affect learners' cognitive structure by providing interaction forms with content. Mental capacity determines individuals' problem-solving capacities as it represents the maximum number of cognitive units that one can deal with simultaneously. Hence, increasing information overloads mental capacity and decreases performance or problemsolving. This contradicts previous studies' results that confirm the relationship between IPL (SL/DL) and mental capacity in the level of treatment (DL/SL) and the indications of CL theory.

\section{QUESTION}

The questions we asked were concerning the different variables, and their interaction, Science MEP:

1) What are the effects of different cues (visual, audio, or both) on Science interactive e-books' learning retention and external cognitive load?

2) And how information processing levels (whether surface or depth level) affect learning retention and external cognitive load within a science subject?

3) Does the interaction between cues (visual, audio, or both) manifest in interactive e-books' information processing levels? If so, does it extend to show in learning retention and external cognitive load on science subjects?

\section{HYPOTHESES}

There are six hypotheses $(\mathrm{H}): \mathrm{H} 1 \& \mathrm{H} 2$ state the following: There are no statistically significant differences between the averages of pupils' scores by testing the LR in science and ECL for MEP due to the difference between the cues types (VC/AC/VAC) in the IeB. H3\&H4 state the following: There are no statistically significant differences in the averages of pupils' scores by testing the LR in science and ECL scale for the MEP due to the difference between the IPL (SL/DL). H5\& H6 state the following: There is no statistically significant effect of the interaction of cues types (VC/AC/VAC) in Iebook with IPL (SL/DL) in the CL scale and LR test for MEP.

\section{METHOD}

First, our research model was designed as an exploratory research method. Our population comprised 117 MEP students in the City of Hail with Science major(s); they were divided into 6 groups.

The research dealt with three variables types: independent variables, Ie-book Cues (VC/AC/AVC); classification variables, IPL (SL-DL); and dependent variables, ECL and LR. This study employed a descriptive-analytical method to analyze previous studies and a quasi-experimental transversal comparison of equivalent groups designed to identify the interaction effect of independent and classified variables on dependent variables, as in table 1:

Table (1) Experimental Design for Research

\begin{tabular}{|c|c|c|c|c|c|}
\hline Experimental & Pretest & Treatment & LIP (SL-DL) & Post Test & $\begin{array}{c}\text { After Tw o } \\
\text { Weeks }\end{array}$ \\
\hline Group 1 & \multirow{6}{*}{ LIP scale } & \multirow[t]{2}{*}{ Ie-book Cues (VC) } & SL & \multirow{6}{*}{$\begin{array}{c}\text { Achievem ent } \\
\text { Test } \\
+ \\
\text { CL Scale }\end{array}$} & \multirow{6}{*}{$\begin{array}{c}\text { Learring } \\
\text { Retention Tes }\end{array}$} \\
\hline Group 2 & & & DL & & \\
\hline Group 3 & & Ie-book Cues (AC) & $\mathrm{SL}$ & & \\
\hline Group 4 & & & $\mathrm{DL}$ & & \\
\hline Group 5 & & Ie-book Cues (AVC) & SL & & \\
\hline Group 6 & & & DL & & \\
\hline
\end{tabular}

\section{A. Data Collection}

First, a list of criteria for designing types for Ie-book was prepared through reviewing some studies [27],[31],[43],[44] related to the criteria for designing tips for the IeB. Then, it was presented to the arbitrators, who amended it. Finally, the final list included two main areas, ten standard levels, 54 indicators.

Second, the achievement test was prepared to measure MEP's LR in IeB's second unit. By developing the table of specifications and the test's relative weights, the number of test questions was determined by 40 items of the type of objective questions, covering scientific concepts in the selected unit while measuring learning outcomes - the test presented to the arbitrators. About $92 \%$ of them were approved. An exploratory experiment was conducted on 20 students. The ease factor for the test items ranged between $0.57-0.82$. The difficulty factor ranged between $0.18-0.43$; both were acceptable. The Alpha Cronbach equation calculated the test's stability, valued 0.89 . So, the results obtained are reliable.

Third ECL scale

Research and CL scales were examined[49],[50]. Then, the ECL scale was prepared, initially including 20 positive and 10 negative items, and four levels of assessment were determined from the student's point of view.

To verify the scale's authenticity, arbitrators weighed it. Agreed-upon phrases were within 80-100\%. The stability coefficient was calculated by the Alpha Cronbach coefficient $(\alpha)$. The items' correlation extent proceeded as in table 2 .

Table (2) Results of the $\alpha$ stability coefficient for the ECL scale

\begin{tabular}{c|c|cc}
\hline Stability Coefficient & No. of Items & No. of a Pilot Sample & Value \\
\hline CronbachCoefficient $(\alpha)$ & 25 & 20 & 0.89 \\
\hline
\end{tabular}

From Table 2, the stability coefficients are 0.89 , highly stable; thus, the ECL scale consists of 25 items.

Fourth: Ie-book instructional design 
Several educational design models were viewed and analyzed [55]-[57]. The Ie-book with cues (VC, AC, AVC) were designed within a hybrid model from the previous models, as in figure 1:

\section{B. Analysis and Identification Stage}

It included seven processes:

First, we focused on identifying the problem: contemporary science e-books were crosschecked with previous research [7],[44][58]-[60]. It was found that the crux of the problem is the diverse content of science, i.e., the presence of many concepts, skills, and experiences, that intertwine into complex decisions.

We surmised that presenting science material should

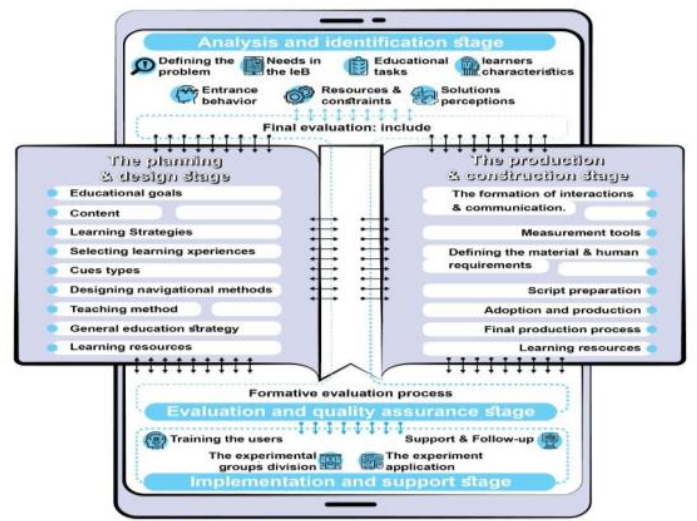

Fig. 2 Educational design model for Ie-book production

facilitate linking concepts and elements, localized in an elearning environment with the consideration of student's levels of processing information. Further focus on cue-cue interactions in interactive e-books and information processing levels and their influence on learning retention and external cognitive load should be assessed.

Second, our focus shifted on the areas of improvement for interactive e-books: according to our examination of MEP's second semester Science textbook, several areas of improvement were pinpointed, such as the need for a cue-rich environment in interactive e-books.

A target was set for the desired performance, where the knowledge of students was crosschecked with each other; a common issue that was found was that all the students found some kind of difficulty when dealing with the science subject. Also, the actual performance of the students was compared with the set goal.

Second, we focused on educational tasks: tasks were ranked from the most to the least important.

Third, we took into consideration learners' characteristics. Pupils were within 12-14 years, capable of imagining and constructing with favoritism toward senses over mental processing; the students were classified into two groups according to information processing level (surface and depth levels).

Fourth, entrance behavior was unified by ensuring that students did not previously interact with cue-rich interactive Science e-books.
Fifth, humans, hardware, and software resources we accordingly allocated for the interactive e-books and the devices availed for the students.

Finally, it was found that the most effective educational solution was availing cue-rich interactive e-books to improve learning retention and reduce the external cognitive load of MEP Science students.

\section{The Planning and Design Stage}

It included nine operations: Educational goals comprised 9 general and 40 behavioral goals. Content goals were period specific. Learning goals were implementing self-learning, discovery learning, and lecture discussion. For each of the goals, learning strategies were appropriated to accommodate individual and group learning styles.

The cues used within the interactive e-books were visual, audio, and audiovisual cues. According to the provided information, navigation of the software was localized and facilitated by keywords, essential elements, lists, allowing moving forward, backward, and in repetition, and exit prompts.

Teachers took into consideration the mix between individual and group learning by appropriating the content according to the students' speed and ability.

The strategy devised by [61] was adopted as follows: motivation by attracting attention, enunciating learning goals, utilizing interactive e-books resources in displaying information, and providing feedback through final exams. The model was also used as a reference to allocating resources through allocating alternatives for each goal and then choosing the most efficient of these alternatives.

\section{The Production and Construction Stage}

It included six operations:

First, the interaction network \& communication methods were identified in the interactive e-books-learners-teachers module, e.g., e-mail, messages, etc.

Second, the research tools were devised, including a learning retention test and external cognitive load and information processing level scales.

Third, the material and human resources requirements were defined as following: the traditional Science book in MEP, interactive e-book production budget, programs producing still and motion pictures. Afterward, a script was prepared introducing the scenario of the interactive e-book including the following: screen number and layout, sound, still images, video clips, graphics, and sequence and compatibility. Arbitrators evaluated the scenario and introduced their adjustments.

Finally, media were selected and appropriated according to the proposed model. Programs were allocated for their media as follows: Microsoft Word for text, Adobe Photoshop $8 \mathrm{CS}$ ME for static images, Macromedia Flash 8 for static images and interactive e-book elements, Swish Max for effects, Aftereffect cs6 for animations and visual effects, and Sound Forge for recording and processing voiceover.

Finally, the final draft underwent some final changes such as background colors, words, addresses, and frames for pictures 
and graphics if needed.

\section{E. Evaluation and Quality Assurance Stage}

It consisted of two basic processes:

Formative evaluation and final evaluation processes, the first took place during the production stage of the interactive ebook. While the final process occurred after implementing the feedback of arbitrators and a survey sample of 32 pupils.

\section{F. Implementation and Support Stage}

It consists of two basic processes:

The teachers were first trained to use the interactive e-book and how to manage the learning process besides preparing students and the necessary material.

The groups were divided into six groups (table 1) according to the information processing level.

Teachers applied the experiment within April 1st-April 10th, 2020, after which students' external cognitive load and learning retention were assessed.

Finally, technical and educational support was provided to the students.

\section{FINDINGS}

\section{A. Limitations}

Four limitations should be mentioned despite the positive results. First is a comparison between some of the cues kinds was presented in the Ie-book with the allusion (VC/AC/AVC) in the science course for MEP. Second, when designing an interactive e-book, some characteristics, including speed, sequence, and media controls, were addressed. Third, the sample size was small and not geographically diverse. Fourth, the long-term effects of learning are limited to three weeks.

\section{B. Results}

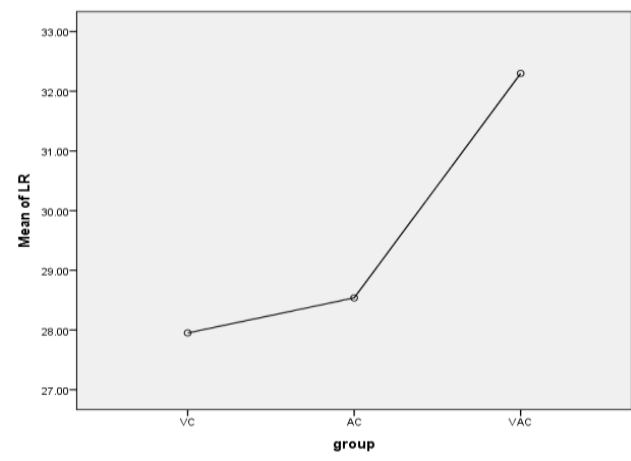

Fig. 3 Shows the differences between the cues types (VC/AC/VAC) in the Ie-book in LR test

To answer Q1, independent sample F-test tested the difference between the effect of the different cues types (VC/AC/VAC) in the Ie-book on the LR in Science with MEP as in table 3:

Table (3) Results of the difference between the cues types in the Ie-book on the LR with Science in the MEP

\begin{tabular}{|c|c|cccc|c|}
\hline $\begin{array}{c}\text { Difference } \\
\text { Between } \\
\text { Groups }\end{array}$ & $\begin{array}{c}\text { Sum of } \\
\text { Squares }\end{array}$ & df & $\begin{array}{c}\text { Mean } \\
\text { Square }\end{array}$ & F & Sig & $\begin{array}{c}\text { Effect } \\
\text { Size }\end{array}$ \\
\hline Within Groups & 1435.324 & 2 & 211.936 & & & \\
\hline Total & 1859.197 & 114 & 12.591 & 16.833 & .000 & $\begin{array}{c}\text {. } \\
\text { Tigh }\end{array}$ \\
\hline
\end{tabular}

The results (table 4 and figure 3) show statistically significant differences between the pupils' scores' averages via testing the LR in Science cource for MEP due to varying cues (VC/AC/VAC) in the IeB. A Tukey post hoc test was used to study the varying cues types (VC/AC/VAC) in the Ie-book in LR test:

Table (4) Post hoc test using the Tukey test shows the varying cues types (VC/AC/VAC) in the Ie-book in LR test

\begin{tabular}{|cc|c|c|}
\hline \multirow{2}{*}{ (I) group } & (J) group & Mean Difference (I-J) & Sig \\
\hline \multirow{2}{*}{ VC } & AC & -.58 & .740 \\
\cline { 2 - 4 } & VAC & -4.34 & .000 \\
\hline AC & VAC & -3.75 & .000 \\
\hline
\end{tabular}

Results show that there are statistical differences between the (VC/VAC) and (AC/VAC) in the Ie-book in LR test for the $\mathrm{VAC}$ but not between $(\mathrm{VC} / \mathrm{AC})$.

The current results agree with studies of [7],[9],[60],[62] that $\mathrm{VC}$ and $\mathrm{AC}$ for $\mathrm{CL}$ are in harmony.

Previous results differ from those of [15],[42],[50]-[52] that $\mathrm{VC}$ is more effective than $\mathrm{AC}$ in directing learners 'attention and reducing CL. However, the clear and effective efficacy of AVC was evident in reducing ECL. Also, results differ from those of [6],[15] showed that using multiple cues hinders multimedia due to CL's burdens. With cues, students could focus and distribute their attention to subject-related information when learning in IeB. AVC provided a more comprehensive treatment of the content, reflected in higher averages in the LR test.

To answer Q2, ANOVA test was used to study the difference between the different effect of cues types

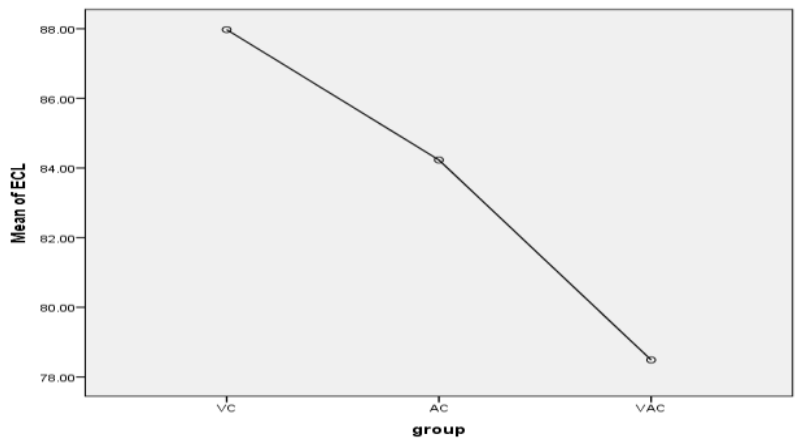

Fig. 4 The differences means between the cues types (VC/AC/VAC) in the Ie-book in ECL scale

(VC/AC/VAC) in the Ie-book on the ECL scale in MEP, as in table 5:

Table (5) Results of the difference between the cues types in the Ie-book on the ECL scale in the MEP 


\begin{tabular}{|c|c|c|c|c|c|c|}
\hline Difference & $\begin{array}{l}\text { Sum of } \\
\text { Squares }\end{array}$ & df & $\begin{array}{l}\text { Mean } \\
\text { Square }\end{array}$ & F & Sig. & $\begin{array}{c}\text { Effect } \\
\text { Size }\end{array}$ \\
\hline $\begin{array}{l}\text { Between } \\
\text { Groups }\end{array}$ & 1766.11 & 2 & 883.05 & 7.68 & .001 & $\begin{array}{l}.793 \\
\text { High }\end{array}$ \\
\hline Within Groups & 13115.14 & 114 & 115.05 & & & \\
\hline Total & 14881.25 & 116 & & & & \\
\hline
\end{tabular}

The results (table 6 and figure 4) showed the statistically significant differences between the pupils' scores' averages on the scale of ECL for MEP due to the varying cues types $(\mathrm{VC} / \mathrm{AC} / \mathrm{VAC})$ in the Ie-book. Post hoc analysis tested the differences between cues types in ECL scale as the following:

Table (6) Post hoc test using the Tukey test shows the varying cues types (VC/AC/VAC) in the Ie-book in ECL scale

\begin{tabular}{c|cc|c|}
\hline \multirow{2}{*}{ (I) group } & (J) group & Mean Difference (I-J) & Sig \\
\hline \multirow{2}{*}{ VC } & AC & 3.74 & .267 \\
\cline { 2 - 4 } & V AC & 9.48 & .000 \\
\hline \multirow{2}{*}{$\mathrm{AC}$} & V AC & 5.74 & .055 \\
\hline
\end{tabular}

Table 6 and fig (4) showed no statistical differences between $\mathrm{VC}$ and $\mathrm{AC}$ and $\mathrm{AC}$ and $\mathrm{VAC}$ in the average score of ECL scale. However, there are statistical differences between $\mathrm{VC}$ and $\mathrm{VAC}$ in the average score of ECL scale for VC.

The previous findings agree with [15],[40],[41],[51],[60],[63],[64] that VC and AVC were effective in directing learners' attention to educational content in multimedia environments. Also, VC reduced ECL and

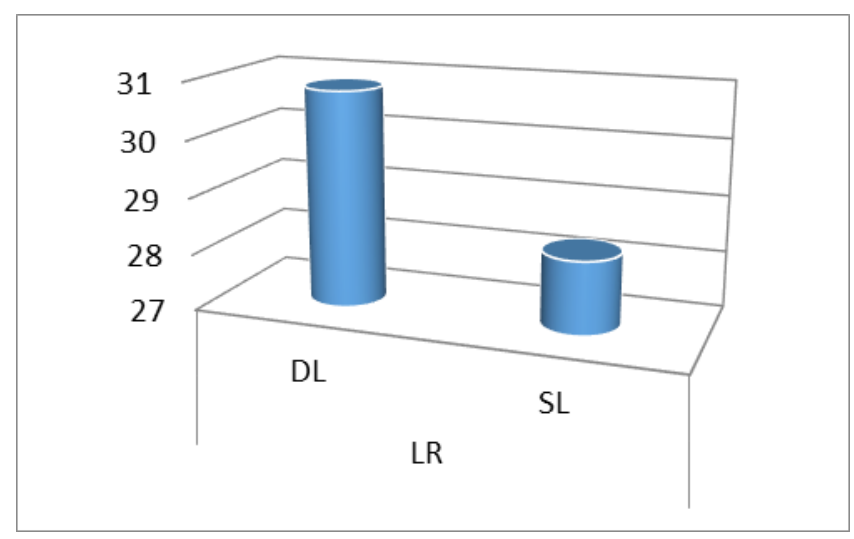

Fig. 5 Differences in the averages between the IPL (SL/DL) in LR in Science

search activities for important information. Also, [40],[42] confirm that VC helps maintaining visual and verbal representations in working memory, though disagreeing with [34], who stated that using AC effectively increased achievement, enhanced understanding, and corrected more $\mathrm{VC}$ errors.

The AVC was more effective than (AC and $\mathrm{VC}$ ) in increasing pertinent $\mathrm{CL}$. As the use of Ie-book for the experimental group (AVC) allowed lesser CL by reducing the invisible CL through supplying learners with only the necessary information needed to accomplish their learning, purifying unnecessary details, and reducing information search activities.

To answer Q3, an independent sample T-test tested the pupils' average score differences by testing the LR in Science for the MEP as a result of the IPL (SL/DL) difference, as in

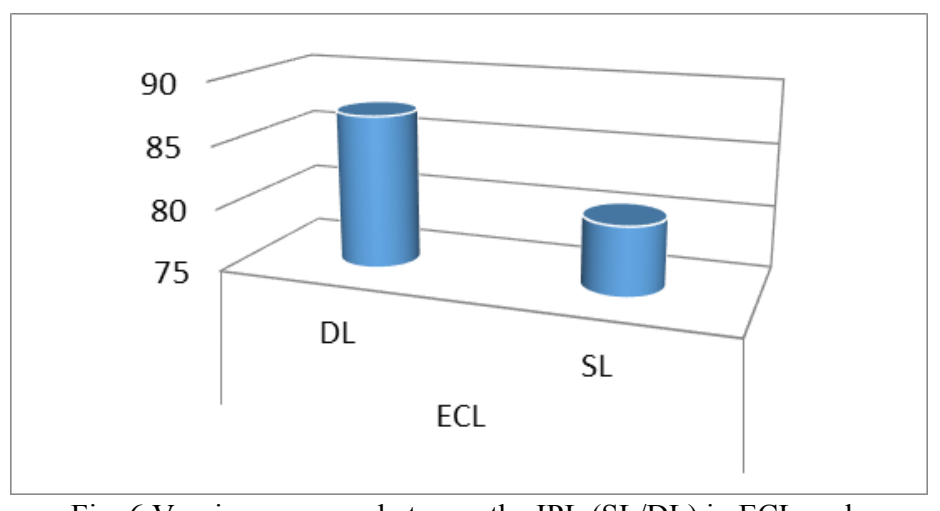

Fig. 6 Varying averages between the IPL (SL/DL) in ECL scale

table 7:

Table (7) Results of the difference between the IPL (SL/DL) in LR in science with MEP

\begin{tabular}{c|cccc|cc|cc|}
\hline Test & IPL & N & Mean & Std & df & t & Sig & $\begin{array}{c}\text { Effect } \\
\text { Size }\end{array}$ \\
\hline LR & SL & 60 & 28.28 & 3.32 & \multirow{2}{*}{115} & 3.61 & $\begin{array}{c}.001 \\
\text { sig }\end{array}$ & $\begin{array}{c}.643 \\
\text { Moderate }\end{array}$ \\
\hline
\end{tabular}

The findings revealed statistically significant variances in the pupils' average scores by testing the LR in Science for the MEP due to varying IPL (SL/DL) for the DL as in figure 5. So, the third hypothesis to "There are statistically significant differences in pupils' averages scores by testing the LR in Science for the MEP due to the difference between the IPL (SL/DL)".

The previous results agree with [8],[45],[59],[65]-[69] indicating that the DL information processing facilitates learning and deep understanding; thus, students outperform with a DL over an SL.

To answer Q4, an independent sample T-test tested the differences in the pupils' average scores by testing ECL scale for the MEP due to varying IPL (SL/DL) as in table 8:

Table (8) Results of the varying IPL (SL/DL) in ECL scale with MEP

\begin{tabular}{|c|c|c|c|cc|cc|c}
\hline Scale & & $\mathrm{N}$ & Mean & Std & df & $\mathrm{t}$ & Sig & Effect Size \\
\hline \multirow{2}{*}{ ECL } & SL & 60 & 80.45 & 12.35 & 115 & 3.35 & $\begin{array}{c}.001 \\
\text { sig }\end{array}$ & $\begin{array}{c}.088 \\
\text { Low }\end{array}$ \\
\cline { 2 - 9 } & DL & 57 & 87.18 & 9.03 & & & & \\
\hline
\end{tabular}

The results (table 8 and figure 6) revealed no statistically significant differences in the mean of students' scores on the scale of ECL for MEP due to varying IPL (SL/DL). So, the fourth hypothesis was accepted.

The previous results agree with [59],[70]-[73] concluding that students with DL information processing maintain high scores on tests without cognitive overload, though differing with [74] that stated no differences in the CL scale resulting from data processing's primary effect (DL/SL).

To answer Q5, the MANOVA test studied the cues types interaction effect (VC/AC/VAC) in Ie-book and IPL (SL/DL) 


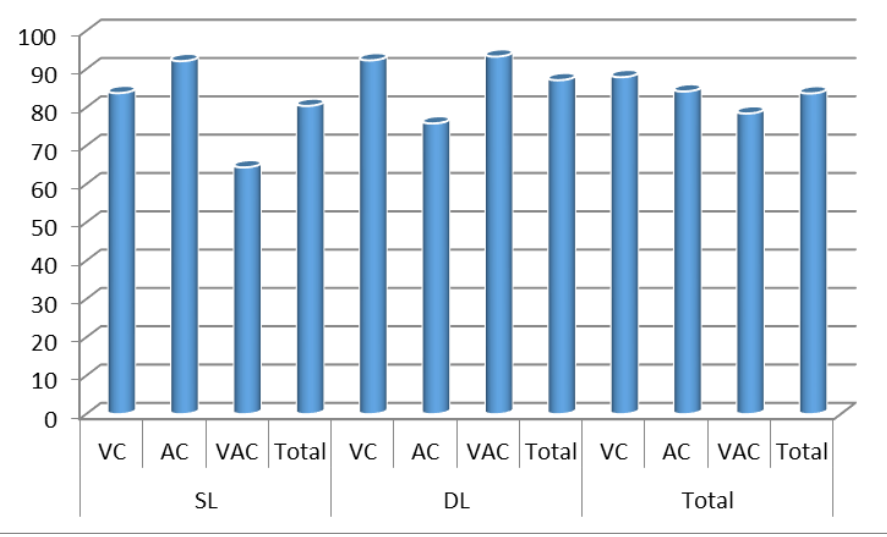

Fig. 7 The interaction between cues types in Ie-book and IPL in ECL scale

in ECL scale for MEP as in table (9):

Tale (9) Results of the interaction between the cues types (VC/AC/VAC) in Ie-book and IPL (SL/DL) in ECL scale

\begin{tabular}{|cc|c|c|c|c|c|}
\hline Source & $\begin{array}{c}\text { Type III Sum } \\
\text { of Squares }\end{array}$ & df & $\begin{array}{c}\text { Mean } \\
\text { Square }\end{array}$ & F & Sig & $\begin{array}{c}\text { Effect } \\
\text { Size }\end{array}$ \\
\hline Corrected Model & 12814.48 & 5 & 2562.99 & 137.64 & .000 & - \\
\hline Intercept & 816998.95 & 1 & 816899.95 & 43873.41 & .000 & - \\
\hline IPL & 1456.81 & 1 & 1456.81 & 78.24 & .000 & .413 \\
\hline Group & 1648.42 & 2 & 824.21 & 44.26 & .000 & .444 \\
\hline IPL * Group & 9729.50 & 2 & 486.75 & 261.27 & .000 & .825 \\
\hline Error & 2066.75 & 111 & 18.61 & & & - \\
\hline Total & 835066.00 & 117 & & & & - \\
\hline Corrected Total & 14881.24 & 116 & & & & - \\
\hline
\end{tabular}

The results revealed that: There were no statistically significant differences between cues types (VC/AC/VAC) in Ie-book in ECL scale for MEP. Also, there were no statistically significant differences between IPL (SL/DL) in ECL scale for MEP. Finally, There was a statistically significant effect of the cues types' interaction (VC/AC/VAC) in Ie-book with IPL (SL/DL) in ECL scale for MEP.

Post hoc test using the Tukey test computed the cues types' interaction (VC/AC/VAC) in Ie-book and IPL (SL/DL) in ECL scale for MEP as the following in table 10:

Table (10) Post hoc test using Tukey test exhibiting

interaction between cues types in Ie-book and IPL in ECL scale

\begin{tabular}{ccc|cc}
\hline IPL & Group & Mean & Std. Deviation & N \\
\hline \multirow{4}{*}{ SL } & VC & 83.81 & 3.72 & 21 \\
& AC & 92.15 & 2.83 & 20 \\
\cline { 2 - 5 } & VAC & 64.42 & 6.26 & 19 \\
\cline { 2 - 5 } & Total & 80.45 & 12.34 & 60 \\
& VC & 92.35 & 2.66 & 20 \\
\cline { 2 - 5 } DL & AC & 75.89 & 5.47 & 19 \\
\cline { 2 - 5 } & VAC & 93.33 & 3.88 & 18 \\
& Total & 87.17 & 9.03 & 57 \\
\hline \multirow{4}{*}{ Total } & VC & 87.97 & 5.38 & 41 \\
\cline { 2 - 5 } & AC & 84.23 & 9.27 & 39 \\
& VAC & 78.48 & 15.53 & 37 \\
\cline { 2 - 5 } & Total & 83.72 & 11.32 & 117 \\
\hline
\end{tabular}

The results (table 10 and figure 7) establish the reaction at its highest peak in the case of the AVC with DL, followed by $\mathrm{VC}$ with DL, and then AC with SL.

The previous results agree with [15],[41],[58],[75] that $\mathrm{AVC}, \mathrm{VC}$, and $\mathrm{AC}$ reduce $\mathrm{CL}$ and research activities to important information. However, results disagree with [7],[76],[77] stating no interaction affecting CL in e-books.

To answer Q6, the MANOVA studied the effect of the cue types interactions (VC/AC/VAC) in Ie-book and IPL (SL/DL) in LR test for MEP, as in table 11:

Tale (11) Results of cues types interaction (VC/AC/VAC)

in Ie-book and IPL (SL/DL) in LR test for MEP

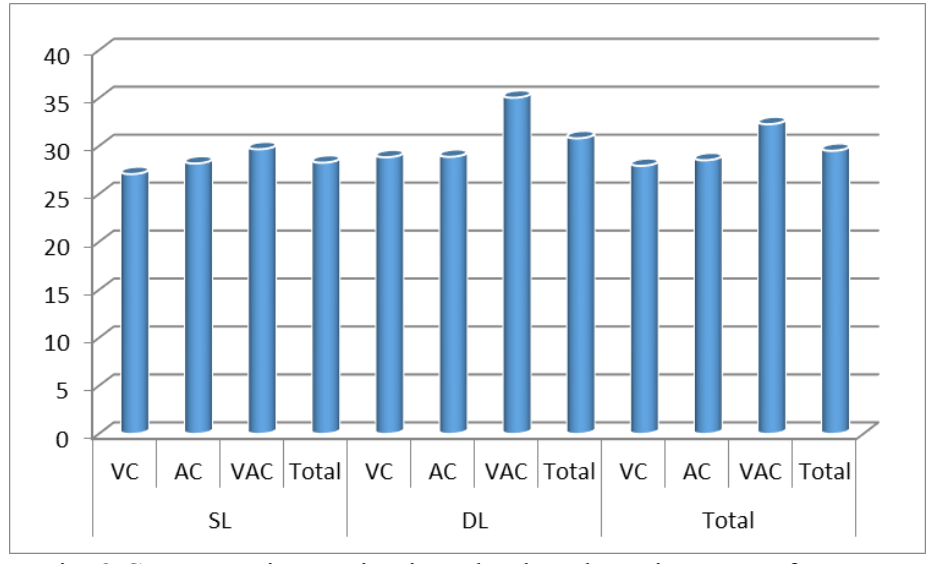

Fig. 8 Cues types interaction in Ie-book and IPL in LR test for MEP

\begin{tabular}{|cc|cc|c|cc}
\hline Source & Sum of Squares & df & $\begin{array}{c}\text { Mean } \\
\text { Square }\end{array}$ & F & Sig. & $\begin{array}{c}\text { Partial Eta } \\
\text { Squared }\end{array}$ \\
Corrected Model & 726.79 & 5 & 145.36 & 14.24 & .000 & - \\
Intercept & 102470.06 & 1 & 102470.06 & 10044.32 & .000 & - \\
P & 198.30 & 1 & 198.30 & 19.43 & .000 & .149 \\
Group & 435.12 & 2 & 217.56 & 21.32 & .000 & .278 \\
\hline IPL * Group & 113.59 & 2 & 56.79 & 5.56 & .005 & .091 \\
\hline Error & 1132.39 & 111 & 10.20 & & & \\
\hline Total & 103826.00 & 117 & & & & \\
\hline Corrected Total & 1859.19 & 116 & & & & \\
\hline
\end{tabular}

The results revealed no statistically significant differences between cues types (VC/AC/VAC) and between IPL (SL/DL) in Ie-book in LR test for MEP. Also, there is a statistically significant effect of cues types interaction (VC/AC/VAC) in Ie-book with IPL (SL/DL) in LR test for MEP.

The post hoc test computed the cues types interaction (VC/AC/VAC) in Ie-book with IPL (SL/DL) in LR test for MEP as the following:

Table (12) Post hoc test using Tukey test shows the cues types interaction in Ie-book and IPL in LR test for MEP

\begin{tabular}{c|cc|cc|}
\hline IPL & Group & Mean & Std Deviation & N \\
\hline \multirow{4}{*}{ SL } & VC & 27.0952 & 2.82674 & 21 \\
\cline { 2 - 5 } & AC & 28.2000 & 2.93078 & 20 \\
\cline { 2 - 5 } & VAC & 29.6842 & 3.81594 & 19 \\
\cline { 2 - 5 } & Total & 28.2833 & 3.32475 & 60 \\
& VC & 28.8500 & 3.09966 & 20 \\
& AC & 28.8947 & 3.17796 & 19 \\
& VAC & 35.0556 & 3.28046 & 18 \\
& Total & 30.8246 & 4.26415 & 57 \\
\hline \multirow{4}{*}{ IPL } & VC & 27.9512 & 3.05738 & 41 \\
\cline { 2 - 5 } & AC & 28.5385 & 3.03355 & 39 \\
\cline { 2 - 5 } & VAC & 32.2973 & 4.44638 & 37 \\
\cline { 2 - 5 } & Total & 29.5214 & 4.00344 & 117 \\
\hline
\end{tabular}

\section{DISCUSSION}

The current study differed from previous studies. The previous studies focused on how to apply technology in the production and design of e-books and its importance in achievement and learning efficiency. Without delving into the individual differences between the learners and measuring the CL associated with them.

Ie-book availed active learning, encouraging students' effectiveness and enthusiasm in studying Science per the design of VC, AC, and AVC through two channels, audio and visual. This maximizes the attention process and perception of 
the visual/audio field for students, increasing the LR and reducing ECL.

The DL-AVC, VC-DL, AC, and SL interactions enhanced attention, appropriate symbols for processing usage, and memory. This increased learner's information retention. Where its recovery after long periods improved, emphasizing the main learning topics and their organization. The elements interplay became more prominent and integrated, synergizing into a coherent representation, emphasizing the two elements' relationship within one representation, and reducing the CL. Besides, the DL allows a deep understanding, increasing LR from the SL.

Students with DL information processing employed mental effort and a greater network of learned interrelationships and knowledge present in memory, facilitating recall and retrieval through stored learning-linked cognitive structures. This agrees with CL theory, thusly reducing it. The subject of learning was then more familiar, allowing the processing of a large number of cognitive elements with spontaneous minimal effort.

The researchers agree with [34],[78] stating that imagesand sound-rich situations are presented (modality effect) more effectively compared with the text-only situations. Providing cues $(\mathrm{AC}, \mathrm{VC}$, or $\mathrm{AVC}$ ) leads to a decrease in the $\mathrm{CL}$ rate through synergetic two-treatments performance. Thus, the working memory can expand the scope of its processability and utilize both information processing tools that increase LR. The researchers explain that the cues strategies helped the process of focusing the learner's attention on the stimuli during the presentation of the content, also made the basic learning characteristics distinct from other stimuli to achieve the uniqueness of education, taking into account individual differences and improving the learning environment.

Also, the study agrees that Ie-books are innovative, likely improving student comprehension and retention [2],[22],[34]. IPL and the cues type maintain interactions [59],[66]. Also, The DL of IPL achieve learning goals [59].

Interpretation of Learning Theories

Per the cognitive theory, learning is enhanced through IeB; cues enhance learners' attention via physical means: highlighting important information, reasoning, and thinking skills in each appropriate teaching while considering the learner's knowledge level. Per the CL theory, the cues (VC or $\mathrm{AC})$ reduce the time and effort spent on working memory thusly decreasing the intrinsic load. Cues organize information by directing students to the most relevant information, ensuring the efficient use of working memory with irrelevant information, and identifying the most suitable information for its LR in working memory.

The Binary Coding Theory emphasized utilizing verbal and nonverbal systems when learning and enhancing learning and information retention due to the two types of mental representations; this increases learning effectiveness. Per the theory, cue-focused verbal and visual information regulation minimized irrelevant information effectively, relieving working memory. The Working Memory Theory agrees as well, exhibiting more efficient working memory, practically, by using both channels simultaneously. [34] Theory of Multimedia Learning, should the visual text be with sound, learning outcomes and multimedia efficiency increase with less mental effort.

Conclusion and Suggestions

Since the study showed better results in LR and CL for pupils with DL levels, we recommend identifying pupils' cognitive characteristics while monitoring their IPL when designing an IeB. Employing cues with different courses facilitate understanding of visual content. Our study prefers AVC due to its results.

Ie-book design cause better comprehension and retention to the users as it helps the students to engage with the topics being discussed. The inclusion of interactive cues such as multimedia elements is a significant part of the specifications. The functions under this specification include links to videos that illustrate the topic being taught and the inclusion of video and audio to strengthen the topic's engagement. Research could help in Ie-book production regarding cues, which can overcome MSP-related difficulties for individual differences. Also, the results of the research may also be useful in providing designers of interactive e-books with standardized guidelines for the appropriate treatment of the production of Ie-books regarding types of cues.

Future studies should focus on Ie-book-IPL interactions besides the effect of different methods of organizing content in Ie-book on developing achievement and metacognition skills and different types of guidance in the Ie-book on developing self-organized learning and motivation of achievement. Iebook features might prove beneficial for learning and should be further explored. Also, The studies should focus on cues strategies are used.

Funding:

Scientific Research at the UOH, KSA funded the search (No. BA-1914). The funding source had no involvement in any aspect of the study design, delivery, or publication.

\section{REFERENCES}

[1] Zhang-Kennedy, L., Abdelaziz, Y., \& Chiasson, S. (2017). Cyberheroes: The design and evaluation of an interactive e-book to educate children about online privacy. International Journal of Child-Computer Interaction, 13, 10-18.

[2] Frye, S. K. (2014). The implications of interactive eBooks on comprehension (Doctoral dissertation, Rutgers University-Graduate School of Education).

[3] Azmy, N. G. (2015). Interactive learning environments, 2nd Edition, Cairo, Dar Al Fikr Al Arabi.

[4] Moreno, R., \& Mayer, R. (2007). Interactive multimodal learning environments. Educational Psychology Review, 19, 309-326.

[5] Sahyouni, R., Mahmoodi, A., Mahmoodi, A., Huang, M., Tran, D. K., \& Chen, J. W. (2017). Interactive eBooks in educating patients and their families about head injury 
regardless of age. Clinical neurology and neurosurgery, 156, 41-47.

[6] Roberts, W., E.(2009). The Use of Cues in Multimedia Instructions in Technology as a way to Reduce Cognitive Load (Doctoral dissertation). State University in partial fulfillment, Carolina.

[7] Salem, M. I. (2017). The Effect of Interaction Between Cues in E- Book and The Information Processing Levels on Primary school students Achievement and Cognitive, $\mathrm{PhD}$ thesis, College of Graduate Studies in Education, Department of Educational Technology.

[8] Kim, D. G.; Lee, J. (2014).A Study on Improving Information Processing Abilities Based on PBL, Turkish Online Journal of Distance Education, ISSN 1302-6488 Volume: 15 Number: 2.

[9] Ali, M. E. (2011). The effect of interaction between the types of visual cues and patterns of interaction in computer programs on achievement and the survival of the impact of learning among mentally handicapped and able to learn, unpublished doctoral thesis, Institute of Educational Studies, Cairo University

[10] Anderson, J., Kehoe, J., Robb, K (2006): The Effects on Levels of processing on remembering and Knowing. (available

at):http://psy.standerson,ac.uk/resources/proj797.html. downloaded Feb.(access in) $27 \mathrm{st} 2015$.

[11] Fathi M. A. (2006): The knowledge foundations of mental formation and information processing, edition (2), Cairo, The Publishing House for Universities.

[12] Youssef M. Q. (2016). Cognitive learning and education strategies, Amman, Dar Al-Masirah Printing and Publishing.

[13] Schnotz, W., \&Kurschner,C.(2007): A reconsideration of Cognitive Load theory Educational Psychology Review, 19(4),469-508.

[14] Moreno, R.\& Mayer, R.(2010): Techniques that increase generative processing I multimedia Learning : Open question for Cognitive Load Theory, pp.153-177.

[15] Atkinson, C., \& Mayer, R. E. (2004). Five ways to reduce PowerPoint overload. Creative Commons, 1.

[16]Ruby, R. K. (2012). The effectiveness of a proposed program in science based on the use of super books and electronic speaking libraries to acquire students of the first cycle of basic education in language schools, scientific concepts and some basic science processes, unpublished doctoral dissertation, Faculty of Education, Fayoum University.

[17] Reformer, M. A. (2013). Designing an interactive e-book for the computer course for high school students in Yemen and its effect on the development of learning outcomes, unpublished $\mathrm{PhD}$ thesis, Institute of Educational Studies, Cairo University.

[18] Nassar, D. A. (2013). The effectiveness of the e-book on developing both the skill of computer maintenance and visual/ spatial intelligence among students of the fourth year, Computer Teacher Division, unpublished Master Thesis, Faculty of Specific Education, Tanta University.
[19]Ahmed, M. A. (2014). The effect of using an e-book based on problem solving in science education on developing some thinking skills for prep students, unpublished master thesis, faculty of education, Menoufia University.

[20] Abdullah, H. A. (2010). The relationship between the method of displaying examples and visual cues in educational computer programs and correcting misconceptions about concepts in science for students of basic education, unpublished master's thesis, faculty of education, Helwan University.

[21] Abdel Aziz, S. S., (2011): The effectiveness of visual hint patterns in the educational computer program on developing the distinction of alphabets and words among kindergarten children, unpublished master thesis, faculty of education, Helwan University.

[22] Intal, G. L. D., \& Talens, J. R. (2019) Ergonomically design e-book to improve comprehension and retention.

Proceedings of the International Conference on Industrial Engineering and Operations ManagementBangkok, Thailand, March 5-7.

[23] Mahmoud, A.\& Syed Y. (2013). The effectiveness of the difference in some patterns of interactive e-book design in developing the skills of designing and producing electronic courses for computer teachers, Journal of Arab Studies in Education and Psychology, Saudi Arabia, 41(1), 145-200.

[24] Korat, O. \& Shamir, A.(2008): The Educational Electronic Book as a tool for supporting children's emergent literacy in low Versus middle SES groups, Computers \& Education, 50, 110-124.

[25] Dünser, A., \& Hornecker, E. (2007, June). An observational study of children interacting with an augmented story book. In International Conference on Technologies for E-Learning and Digital Entertainment (Pp. 305-315). Springer, Berlin, Heidelberg.

[26] Azmy, N. G., and El-Mouradni, M. M. (2010). The effect of interaction between different types of structural learning supports within the e-book on achievement and learning efficiency of graduate students at the Faculty of Education, Journal of Educational and Social Studies, 16 (3), Helwan University, 252-321.

[27] Saad, A. S. (2011a). The effect of the interaction between the navigation structure within the e-book and cognitive methods on developing problem-solving skills, unpublished $\mathrm{PhD}$ thesis, College of Education, Ain Shams University.

[28] Saad, S. A. (2011b): The effectiveness of individual selflearning by computer and e-book simulation in developing innovative thinking among science students in the second year, Faculty of Education, Sultanate of Oman (experimental study), Scientific Journal, College of Education, Assiut University, 27(2), 101-139.

[29] Ghandour A. A. (2012): The effect of using the e-book in developing electronic scheduling skills for prep students, 
Master Thesis, Institute of Educational Studies, Cairo University.

[30] Al-Omari, M.\& Shebl, I (2012): The effectiveness of using an e-book in the subject of reading the achievement of first-year secondary students, Journal of Reading and Knowledge, 133(1), November, 41-88.

[31] Mohamed, S. A. (2007): Criteria for designing visual stimuli for literary materials and their effectiveness in academic achievement for high school students, unpublished Master Thesis, College of Education, Helwan University.

[32] Lin, I. J. (2009). The effects of e-books on EFL learners' reading attitude. Unpublished master thesis. National Taiwan Normal University, Taiwan.

[33] Glackin, B. C., Rodenhiser, R.W., \& Herzog, B. (2014). A library and the disciplines: A collaborative project assessing the impact of e-books and mobile devices on student learning. The Journal of Academic Librarianship, 40, 299-306. doi:10.1016/j.acalib.2014.04.007.

[34] Morris, N. P., \& Lambe, J. (2017). Multimedia interactive e-books in laboratory bioscience education. Higher Education Pedagogies, 2(1), 28-42.

[35] Khamis, M. A., (2013). Educational theory and research in educational technology, 1st floor, Cairo, Dar Al Sahab.

[36] Sweller, J. \& Pass, F.(2012): An evolutionary upgrade of cognitive load theory : using the human motor system and collaboration to support the learning of complex cognitive tasks, Educational Psychology Review, (24),27-45.

[37] Jewitt, C. (2008). Multimodality and literacy in school classrooms. Review of research in education, 32(1), 241267.

[38] Malone, T. \& Lepper, M. (1987). Making learning fun: A taxonomy of intrinsic motivations of learning. In R. E. Snow\& M. J. Farr (Eds.), Aptitude, learning, and instruction: Vol. 3. Conative and affective process analyses (pp. 223-253). Hillsdale, NJ: Lawrence Erlbaum.

[39] Dalton, B., \& Proctor, C. P. (2008). The changing landscape of text and comprehension in the age of new literacies. Handbook of research on new literacies, 297324.

[40] De Koning, B. B., Tabbers, H. K., Rikers, R. M. J. P., \& Paas, F. (2010). Learning by generating vs. receiving instructional explanations: Two approaches to enhance attention cueing in animations. Computers \& Education, 55(2), 681-691.

[41]De Koning, B , Tabbers, H.K, Rikers.R.M \& Pass, F.(2011): Attention cueing in an instructional animation: the role of presentation speed, computers in Human Behavior, 27, 1, pp.41-45.

[42] Ahmed, M. A. (2012). The effect of using visual cues in the online course to correct common grammatical errors in the writings of prep students, unpublished master thesis, faculty of education, Helwan University.

[43] Al-Hindawi O. S., Al-Jizawi, S. I. (2008): The effectiveness of the difference in the number of visual cues in educational computer programs in developing maps reading skills for fourth grade primary students,
Journal of the College of Education, Helwan University, Maj (14), p (2) April.

[44] Abdel Aziz, S. A. (2013). The effect of visual cues of multimedia presentations for the hearing impaired in developing the computer program's skills, master thesis, faculty of education, Fayoum University.

[45]Dinsmore, D. L., \& Alexander, P. A. (2012). A critical discussion of deep and surface processing: What it means, how it is measured, the role of context, and model specification. Educational Psychology Review, 24(4), 499-567.

[46] Youssef, S. A. (2011). Readings in Cognitive Psychology, Cairo, Thebes Foundation for Publishing and Distribution.

[47] Qasim, A. M. (2003): The Psychology of Memory, Recent Issues and Trends, 290 (1), The World of Knowledge, Kuwait.

[48] Ibrahim, U. M. (2017). Building a developed e-portfolio based on the theory of information processing, selfevaluation and peer evaluation and its impact on developing personal knowledge management skills and reducing knowledge burden, International Journal of Internet Education, December, 198-275.

[49] Sweller, J.(2005): Implication of Cognitive Load theory for Multimedia Learning . In r.e.mayer (Ed.

[50]Crooks, S. M., Cheon, J., Inan, F., Ari, F., \& Flores, R. (2012). Modality and cueing in multimedia learning: Examining cognitive and perceptual explanations for the modality effect. Computers in Human Behavior, 28(3), 1063-1071.

[51]Lin, L.(2011): Learning with Multimedia: Are Visual Cues and Self-Explanation Prompts Effective?, A Dissertation Presented in Partial Fulfillment of the Requirements for the Degree Doctor of Philosophy, Arizona State University.

[52] Mayer, R\& Moreno, R. (2010). Techniques That Reduce Extraneous Cognitive Load during Multimedia Learning, University Press, Cambridge.

[53] Shaheen G. A. (2008). The effect of learning style and self-esteem on the level of information processing of a sample of students of the College of Education in the Kingdom of Saudi Arabia, Journal of the College of Education, Mansoura University, (68), 304-354.

[54] Hassan, A. H. (2018). The motivation for academic achievement and performance as determinants of the cognitive load of adolescents from undergraduate students (a predictive study), Journal of Scientific Research in Arts, 19 (10).

[55]Elgazzar, A. E. (2014). Developing E-Learning environments for field practitioners and developmental researchers: A Third Revision of an ISD Model to Meet E-Learning and Distance Learning Innovations. Open Journal of Social Sciences, 2(2), 29-37.

[56] Khamis, M. A., (2015). E-learning resources - Part 1: Individuals and media, Cairo, Dar Al-Sahab for publication and distribution.

[57] Azmy, N. G. (2017). Instructional Design Evolution, Part Two, Encyclopedia of Educational Technology 
[58] Chen, C. H., \& Huang, K. (2014). The effects of response modes and cues on language learning, cognitive load and self-efficacy beliefs in web-based learning. Journal of Educational Multimedia and Hypermedia, 23(2), 117-134.

[59] Dikbas Torun, E., \& Altun, A. (2014). The effect of levels of processing with navigation design types on recall and retention in e-learning environments. Behaviour \& Information Technology, 33(10), 1039-1047.

[60] Liang, T. H. (2015). The effects of keyword cues and 3R strategy on children's e- book reading. Journal of Computer Assisted Learning, 31(2), 176-187.

[61] Khamis, M. A., (2006). The Technology of Learning Resources Production, 1st Edition, Cairo, Dar Al-Sahab.

[62] Milligan, C., \& Littlejohn, A. (2014). Supporting professional learning in a massive open online course. International Review of Research in Open and Distributed Learning, 15(5), 197-213.

[63] Allen, C. G. (2011): The Effects of Visual Complexity on Cognitive Load as Influenced by Fields Dependency and Spatial ability. A doctoral dissertation, Steinhardt School of Culture, Education and Human Development, New York University.

[64] Iravani, H., \& Ghasemi, M. D. (2012). A comparison of using three different types of cues, elaborated context, semantic frames and meaning chains, in disambiguating polysemous verbs. International Journal of English Language Education, 1(1), 109-129.

[65]Xie, Y., Ke, F., \& Sharma, P. (2008). The effect of peer feedback for blogging on college students' reflective learning processes. The Internet and Higher Education, 11(1), 18-25.

[66] Hilla, I. M. (2010). Levels of information processing and its relationship to critical thinking and academic specialization among Taif University students, Arab studies in Education and Psychology, Fourth Issue, October, 255-315.

[67] Al-Banna, H. A., (2011): Skills and levels of information processing and its relationship to the cognitive style (accreditation / independence from the field) among Taif University students, Journal of Arab Studies in Education and Psychology, 5 (3), pp. 15-50.

[68]Hilla, A M.\& al-Qurashi, K. D., (2011): Levels of information processing and its relationship to the mental capacity of Taif University students, Journal of Arab Studies in Education and Psychology, 5 (4), pp. 561-584.

[69] Al-Hawiji, K. (2014). The relationship between levels of information processing and learning style among students of King Faisal University in the Kingdom of Saudi Arabia, Arab studies in education and psychology, No. (45), first part, January 49-109.

[70]Rashwan, R. A. (2003). Strategies for encoding information in memory and its impact on the level of performance in some verbal and formal tasks among primary, middle and high school students, unpublished Master Thesis, Faculty of Education in Qena, Al-wady Algadid.

[71] Ramadan, H. A. (2005): The interaction between some metacognition strategies and levels of information processing in developing scientific concepts and critical thinking among first-grade middle school students in the subject of science, Scientific Education Journal, Issue 8, 181-236.

[72] Al-Harbi, M. A., (2012). Differences in the level of information processing of high and low memory capacity in light of the different strategies of processing and cognitive speed among university students, Imam Muhammad bin Saud Islamic Journal, Humanities and Social Sciences, Saudi Arabia, 24, 143-192.

[73] Rudner, M., Karlsson, T., Gunnarsson, J., \& Rönnberg, J. (2013). Levels of processing and language modality specificity in working memory. Neuropsychologia, 51(4), 656-666.

[74]Al-Ahmadi, S. A. (2015). The effect of intercourse between the density of links in web pages and mental capacity on cognitive load and academic achievement in science subject for high school students in the Kingdom of Saudi Arabia, unpublished doctoral thesis, Faculty of Specific Education, Ain Shams University

[75] Saleh, I. S. (2013): The effect of the interaction between visual cues and cognitive style in the e-book on cognitive achievement, skill performance and ease of use among students of the second stage of basic education, Egyptian Society for Educational Technology, Mag (23), No. (1), January.

[76] Woody, W. D., Daniel, D. B., \& Baker, C. A. (2010). Ebooks or textbooks: Students prefer textbooks. Computers \& Education, 55(3), 945-948.

[77] Marion, E., (2014). Macro-Scaffolding: Contextual Support for Teacher Learning, Australian Journal of Teacher Education, Volume(39) Issue (5).

[78] Segers, M., Gijbels, D., \& Thurlings, M. (2008). Shortand Long- Term modality Effect in multimedia Learning, Educational Studies, 34 (1), pp. 35-44

Dr. Usama M. Ibrahem: has many researches and books in the field of educational design, e-learning, and educational design models, as well as distance training programs and the development of technological skills, and a publication has four books in the field of educational technology.

Dr. Saleh A. Alkhabra: holds a Ph.D. in Educational Technology from University Teknologi MARA (UiTM), MSc in Education Research (2011) from Exeter University(EX), and MSc in Educational Technology (2007) from Umm AlQura University (UQU), Also, he incited and presented many E-training courses nationally and globally.

Dr. Bader A. ALharbi: holds a master's and a doctorate in curriculum and teaching methods from the University of Exeter in Britain. A researcher in national curricula and standards for public education curricula in the Kingdom of Saudi Arabia and 21st century skills.Internal auditor for the National Standards Program for General Education Curricula of the Education Evaluation Commission. He worked in many committees inside and outside the university and also attended and presented many courses inside and outside the Kingdom. 
INTERNATIONAL JOURNAL OF EDUCATION AND INFORMATION TECHNOLOGIES

DOI: $10.46300 / 9109.2021 .15 .7$

\section{Creative Commons Attribution License 4.0 (Attribution 4.0 International, CC BY 4.0)}

This article is published under the terms of the Creative Commons Attribution License 4.0

https://creativecommons.org/licenses/by/4.0/deed.en_US

Appendix

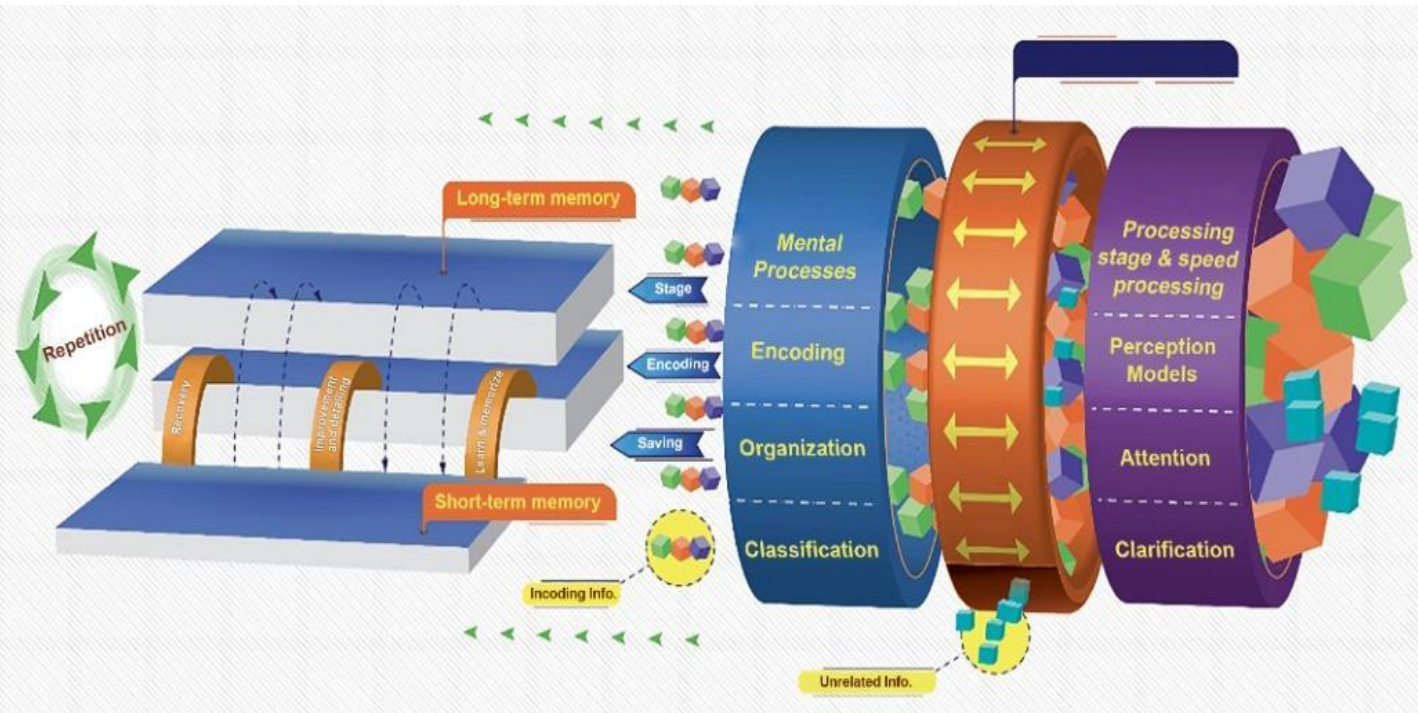

Information

$<\&<\&<<<$

Receiving

information

stage

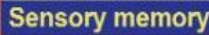

Sensory memory

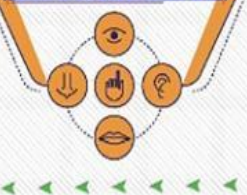

Raw

Perception

Fig. 1 Stages of processing information by Ibrahem (2017)

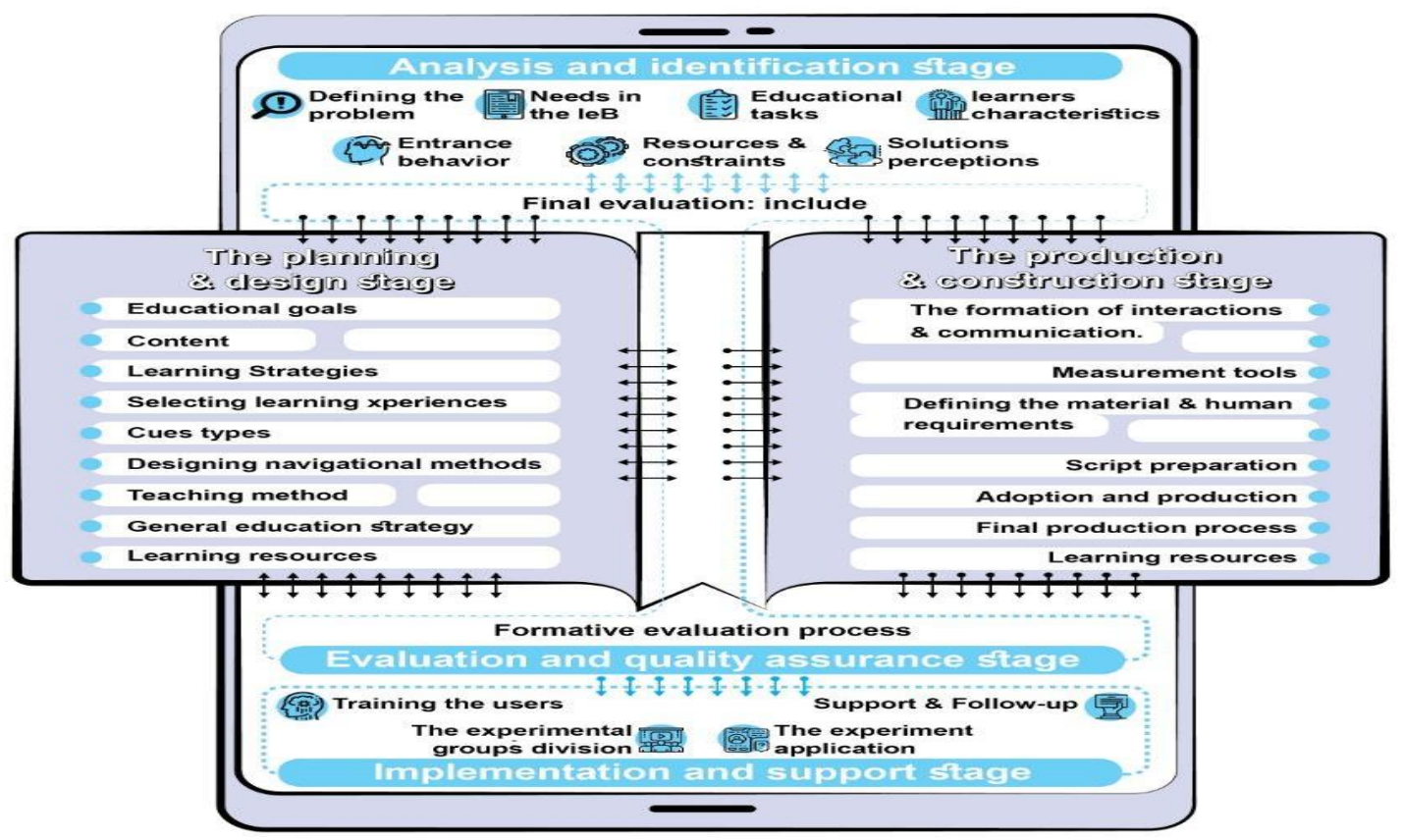

Fig. 2 Educational design model for Ie-book production 